\title{
Endogenous Technology Sharing in R\&D Intensive Industries
}

\author{
Derek J. Clark and Jan Yngve Sand \\ Tromsø University Business School, University of Tromsø
}

\begin{abstract}
This paper analyses endogenous formation of technology sharing coalitions with asymmetric firms. Coalition partners produce complementary technology advancements, although firms do not co-operate on $R \& D$ investment level or in the product market. The equilibrium coalition outcome is either between the two most efficient firms, or a coalition with all three firms. The two-firm coalition is the preferred outcome of a welfare maximising authority if ex ante marginal cost is sufficiently high, and the threefirm coalition is preferred otherwise. Furthermore, we show that the equilibrium outcomes result in the lowest total $R \& D$ investment of all possible outcomes. Aircraft engine manufacturing provides a case study, and indicates the importance of antitrust issues as an addition to the theory.
\end{abstract}

Special issue

The Knowledge-Based Society: Transition, Geography, and Competition Policy

JEL L11, L13

Keywords R\&D; endogenous coalitions; asymmetric firms

Correspondence Jan Yngve Sand, Tromsø University Business School, University of Tromsø, NO-9037 Tromsø, Norway, Tel. +4777645540, e-mail: jan.sand@uit.no 


\section{Introduction}

In this paper we analyze the endogenous formation of technology sharing partnerships, or coalitions, in industries with a limited number of firms. In terms of the treatment in competition policy cases, R\&D mergers or Research Joint Ventures (RJVs) are treated as exception from the prohibition of cooperation (e.g., Article 81 in EU Treaty of Rome which deals with agreements among firms, and the National Cooperative Research Act of 1984 in the U.S.). In particular, the European Commission has issued guidelines on the applicability of Article 81 of the EC Treaty to horizontal cooperation that encompasses R\&D cooperation, and acknowledge that such cooperations may have significant economic benefits through risk sharing, cost savings and the ability to launch new technologies faster than without such cooperation. ${ }^{1}$ RJVs can take various forms, ranging from simple information sharing arrangements with non-cooperative investment decisions by separate $R \& D$ units, to fully integrated $R \& D$ units where investment decisions are made to maximize joint profits. A primary reason for the benevolent treatment of RJVs is that there is a public good aspect to R\&D which may make it difficult to achieve socially optimal levels of R\&D activity if focusing exclusively on non-cooperative R\&D. A major determinant in forming RJVs is the development of new technologies that in turn may reduce production costs. Although allowing the formation of a RJV does not directly affect the market structure in the final product market, efficiency effects from the RJV may have an impact on the market share of the participating firms with increasing dominance as a result. ${ }^{2}$

An important aspect of public policy with respect to R\&D in many countries is the focus on how to increase R\&D levels to the OECD average. ${ }^{3}$ Although this is a useful starting point, the total level of R\&D is not necessarily the most appropriate measure of success as the characteristics of the R\&D intensive indus-

\footnotetext{
${ }^{1}$ See Commission Notice, Guidelines on the applicability of Article 81 of the EC Treaty to horizontal cooperation agreements, 2001/C 3/02), and in particular, Commission Regulation (EC) No 2659/2000 of 29 November 2000, on the application of Article 81(3) of the Treaty to categories of research and development agreements.

${ }^{2}$ See Gugler and Siebert (2007) for an extensive overview of the literature, and for evidence on market power versus efficiency effects on mergers and RJVs.

${ }^{3}$ The Norwegian government has discussed this in a White Paper: St. Prp 51 (2002-2003) Virkemidler for et innovativt og nyskapende næringsliv (Innovasjonsmeldingen).
} 
tries also matter. The present analysis is exclusively focused on firms' privately financed R\&D investments, and we do not look at R\&D undertaken and financed by public funds. Consequently, the R\&D levels we observe in the context of the present model is only half the picture. As we show below, the equilibrium coalition outcome is the least desirable outcome if the main objective is to increase R\&D investments. This would imply that if competition policy authorities allow such a coalition to go through, the public sector will need to finance an even larger share of the total R\&D investments to achieve a higher level of investments. This may quite possibly be seen as good news for universities and research institutes.

We consider a simple type of R\&D cooperation, and focus on coalition formation with technology sharing in a static game. By this we mean that coalition partners benefit fully from any technological advancements that their partner undertakes, but the investment decisions are taken non-cooperatively. There is no benefit of the R\&D undertaken by the coalition partners for the firm outside the arrangement. Thus, there is perfect spillover within the coalition and zero spillover to the outsider. This set-up could also be interpreted as one in which patent holders enter into a patent pool, with each member of the pool being allowed to (costlessly) utilise cost reducing technology advancements made by their partners. ${ }^{4}$ The endogenous formation of the coalition, or pool, will then determine the scope of the pool (i.e., how many, if any, pool partners will there be). There is also some resemblance to the literature on open source, which by some authors is termed collective invention. ${ }^{5}$ The sharing of technology advancements in the present analysis also bears some resemblance to the theory of club goods, where the members of the club can benefit from all the facilities of the club. ${ }^{6}$

There are three firms in our model that all have different ex ante levels of marginal cost in producing the final product. The firms undertake R\&D investments which we model as a type of process innovation, where the investments reduce the marginal cost (of producing the final product) for both the investing firms and

\footnotetext{
${ }^{4}$ For analysis of the welfare effects of patent pools in a different setting see Lerner and Tirole (2004).

${ }^{5}$ On open source see, e.g., Lerner and Tirole (2005). The term collective invention is often attributed to Allen (1983) and describes "the free exchange of information about new techniques and plant designs among firms in an industry".

${ }^{6}$ Buchanan (1965) is the seminal article on the theory of club goods.
} 
that of its coalition partners. ${ }^{7}$ The type of R\&D undertaken should be thought of in terms of implementation of new technology rather than the discovery of new processes, since there is no uncertainty with respect to the outcome of the R\&D investment. The three firms compete in quantities in the product market, and we assume that there is no cooperation other than the potential to share technological advancements among coalition partners. The R\&D investments undertaken by coalition members are thought of as complementary, so each unit of cost-reducing R\&D by firm $A$ in the coalition can be added to each unit of cost-reducing R\&D by firm B. The specification of the cost function, with the effect of R\&D on costs and the ex ante asymmetry between firms allow us to shed light on the distributional effect across firms on R\&D expenditure of forming technology sharing coalitions. This is contrary to the focus on total R\&D expenditure maintained by the majority of the literature.

\section{Related Literature}

We focus on the potential outcomes of either coalitions with two firms, the case with no coalition, and the monopoly (or grand) coalition with all firms participating. In addition, we rank the various outcomes in terms of impact on industry profit, consumers' surplus and ultimately on welfare. Although our primary focus is not on mergers, we make use of the methodology developed by Horn and Persson (2001) to characterize the equilibrium coalition structure and to investigate the impact on R\&D investment levels of the potential outcomes. A similar set of criteria to determine the equilibrium market structure is also employed by Barros (1998) in a paper on endogenous mergers. ${ }^{8}$ None of these papers consider efficiency enhancing investments which is the case for the present paper.

The equilibrium coalition is a result of a cooperative bargaining process in which firms can communicate freely with each other and are free to write binding contracts with each other (Horn and Persson, 2001). There are other papers

\footnotetext{
${ }^{7}$ Some stylised facts on what is termed "informal knowhow sharing" in various industries can be found in von Hippel (1987). Carter (1989) investigates the economic incentives behind sharing of technical information.

${ }^{8}$ Vasconcelos (2006) considers endogeous mergers in endogenous sunk cost industries to derive upper bounds on concentration.
} 
that investigate merger formation, and the three main paths to analysing endogenous mergers are: i) Model the process as a normal form game with bids and asking prices (Kamien and Zang, 1990, 1991), ii) Merger formation as a noncooperative bargaining process (Chatterjee et al., 1993, and Ray and Vohra, 1999), and iii) Merger formation as a cooperative game (Horn and Persson, 2001). The present paper follows the third approach. In this methodology, the focus is on the outcome of the merger process rather than the process that leads to the ultimate coalition. Firms are free to enter into cooperative arrangements with others, and may also attempt to break up existing coalitions. Intuitively, the ultimate coalition will be such that all participating firms gain more than at the outset and that no non-participating firm can offer any of the coalition members a more attractive proposition. ${ }^{9}$ Goyal and Moraga-Gonzáles (2001) consider the incentives for forming pairwise, non-exclusive collaborative R\&D arrangements, and their model allows for a rich set of possible collaborations. The degree of firm rivalry is essential in explaining which collaboration will prevail, and it is suggested that high degree of competition may lead to excessive incentives to collaborate. The analysis in the present paper follows the coalitions approach, in which one player can only belong to one group.

Previous literature indicates that practical use of the endogenous merger methodology necessarily requires some major simplifying assumptions. Banal-Estanol et al. (2008) consider coalition formation between three identical managers who can make cost-reducing investments that are either zero or an exogenously fixed constant level. The emphasis is on the interplay between the merger and investment decisions, and the aim is to shed light on why some mergers fail to realise efficiency gains. The paper consequently extends the literature on horizontal mergers by endogenising the efficiency gains. A similar approach is taken by Bartolini (2008) who considers the interplay between cost reduction and merger strategy. Firms are ex ante identical, they face a binary investment decision of acquiring a cost-reducing asset or not, and after the investment decision is taken firms may merge (or form coalitions) to change the market structure. Firms then compete in quantities in the product market according to the market structure that materialises. The investment decision affects the potential synergies of a mer-

\footnotetext{
${ }^{9}$ Details are discussed in Section 8 .
} 
ger, and there is no synergy if not at least one of the merging firms has invested. The trade-off facing firms when deciding on whether to enter into a coalition is between the positive externality effect of joining a coalition (termed the "Stiegler effect") and the negative externality effect (synergy effect). The first effect provides firms incentives to stay out of the coalition when competing in quantities, but when considering the cost saving effect of being part of the coalition it may induce firms to enter a coalition when the cost is high relative to the size of the market. Without the synergy effect (i.e., no investment), we are essentially in the same scenario as Ray and Vohra (1997) and Bloch (1996) and the grand coalition (monopoly) would form. Our analysis seeks to extend the current literature to investigate asymmetric firms and contrary to the papers by Bartolini (2008) and Banal-Estanol et al. (2008), we assume ex ante asymmetric firms and also endogenise the size of the efficiency investment (through process innovation).

Methodologically, our work is related to Straume (2006). In considering endogenous merger between three asymmetric firms, Straume (2006) finds it necessary to restrict the type of asymmetry between firms to be symmetrically distributed. The focus in his paper is on how the internal organisation of the firm, specifically through managerial delegation, affects the incentives to merge in exogenously asymmetric industries. The present paper differs from Straume (2006) in that we consider endogenous coalition formation with both ex ante asymmetric firms and endogenous cost-reducing investments. Belleflamme (2000) demonstrates that the formation of a grand coalition in endogenous merger models is critically dependent upon the assumption of symmetric firms. In a cost-reduction model in which firms are asymmetric and compete in quantities in the product market, he obtains results for coalition formation based upon the simplifying assumption that only two types of coalition are possible. Similarly, extensions of d'Aspremont and Jacquemin's (1988) seminal work on R\&D incentives to the case of asymmetric firms has required some major simplifying assumptions. For example, Halmenschlager (2004) considers R\&D cooperation in a model with asymmetric firms where two high-cost firms face a technological leader. The latter firm does not engage in $\mathrm{R} \& \mathrm{D}$, so the question posed is under which conditions the laggards can gain from sharing R\&D. In the current paper we use the endogenous merger methodology to look at the sharing of and endogenous level of complementary R\&D between firms with different levels of efficiency. In the light of our previous discussion, 
the level of ambition here is tempered by what is practically possible. As such we adopt the same assumption on asymmetry as in Straume (2006) in assuming that the initial cost difference between firms is symmetrically distributed. Whilst this leads to a stylised model, we postulate that the phenomena and mechanisms that we identify will have wider applicability. The R\&D market game that arises from each coalition structure can easily be solved for the general case, but identifying the coalition that fulfills the conditions for being the endogenous equilibrium structure is not possible.

One main feature of the approach of Horn and Persson (2001) is that the lack of restrictions on the contracts between coalition partners implies that the free-riding problem becomes less pronounced, and one would expect the solution for the equilibrium market structure to become more efficient. In a three firm model with cost asymmetry, we show that the equilibrium coalition may either be between the two most efficient firms, or the grand coalition with all firms. It is not necessarily obvious that the most efficient (and hence) largest firms would choose to share their technology advancements. Our model predicts a result along the line of "keep your friends close, but your enemies closer". One might initially be tempted to deduce that the more efficient firm would prefer to go into partnership with the least efficient firm, or that the two least efficient firms would join forces to be able to outcompete the ex ante most efficient firm. This, however, turns out not to be the case here. The three-firm coalition will emerge as the equilibrium structure when the potential for innovation is low and the cost of investment high. This is reasonable since firms would want to invest less, and the grand coalition results in the lowest level of total $\mathrm{R} \& \mathrm{D}$. In addition, the analysis of mergers often reveals conflicting interests between social and private merger incentives. This is, in particular, due to the fact that the mergers that are chosen endogenously are mergers that result in high industry profit, which is often deemed to be incompatible with high consumers' surplus. In the present analysis, however, the endogenously chosen coalition is also the coalition that maximizes welfare and the coalition that achieves the highest industry profit is also the coalition that results in the highest total output. The important distinction to traditional mergers is naturally that in the present paper we analyse research cooperation, which has the efficiency effect without the increasing concentration effect. 
Our approach is related to that of endogenous spillovers in that the formation of a coalition has implications for spillovers between firms. By agreeing to join a coalition with one or two competitors, the partners implicitly agree to share technology advancements. This is similar in many respects to firms deciding how much of the technology advancements should be transferred to rival firms (i.e., how large is the spillover parameter chosen to be). The importance of the degree of spillover for innovative activity is studied by numerous authors (see, e.g., De Bondt, 1997, for an overview). Gil Molto et al. (2005) analyse a situation where firms endogenously choose the design of the R\&D process, where more compatible R\&D technologies leads to higher degrees of spillover. Related to this is also the literature on absorptive capacity and spillovers, with Kamien and Zang (2000) and Wiethaus (2005) as examples of this avenue of research. The main idea there is that firms choose (endogenously) R\&D approaches, idiosyncratic or broad approaches, which again have implications for the degree of spillovers. These papers come to different conclusions with respect to the choice of R\&D approaches by competing firms. Furthermore, if the firms undertaking R\&D can protect their inventions by the use of some kind of patent protection, this is also in effect a way of limiting the degree of spillover from the investing firm to its rivals. This is analysed in, e.g., Milliou (2009). The present analysis is also complementary to Kabiraj and Mukherjee (2000). They consider a three-firm game with quantity competititon, with the product market cooperation being endogenously chosen. For cooperation in R\&D, they consider both knowledge sharing and Research Joint Venture, but only two firms are allowed to cooperate. They consider the effect of allowing cooperation at the $R \& D$ stage on the incentives to merge at the production stage, and how mergers at the production stage may affect the organisation of the R\&D cooperation. Contrary to the present apporach, firms are ex ante symmetric and only two of the firms are capable of doing R\&D.

In spite of this, technology sharing can potentially have competition effects, and hence we look at our conclusions from the theoretical model in the light of EU competition law, and a case study from aircraft engine manufacturing. Whilst we find support for the type of technology sharing that we are considering, and document that this may well be required by law, there is a discrepancy between our prediction for the equilibrium coalition and our observations from the case study. Hence, it would appear that competition law prevents the type of coalition 
structures that would appear endogenously, given the market structure, due to the effect of limiting the potential competition.

Our theoretical result depends on the balance between a free-riding effect and efficiency effects within the coalition, and although the market structure in the product market is unaffected by the various coalitions, the aggressivity of competition in the product market may be affected. A seminal contribution on the effect of industry structure on the level of innovation is Dasgupta and Stiglitz (1980). In their paper they treat both industry structure and the nature of the innovative activity as endogenous, and they construct a theoretical model consistent with empirical facts that does not make assumption about causality between concentration and innovation. Similarly, Vickers (1986) investigates the relationship between the evolution of market structure and R\&D with sequential, non-drastic innovations. ${ }^{10}$ The innovative process is modelled as a sequence of patent races. The main question posed is what determines whether an industry becomes increasingly dominated by one firm, or whether market leadership changes between firms over time. His main result suggests that the intensity of the product market competition determines whether there is increasing dominance, or changing market leadership. If the product market is highly competitive (Bertrand-competition) there is increasing dominance, but when competition in the product market is less intense (Cournot) then there may be changing market leadership over time as the increase in potential product market profit increases the incentives to undertake cost-reducing R\&D. A more recent contribution on the relationship between the product market competition and innovation is Aghion et al. (2005). Innovation incentives depend in their model on the difference between pre-innovation and post-innovation rents, and if competition reduces a firm's pre-innovation rents more than it reduces post-innovation rents increased competition may lead to increased innovation. The theoretical model predicts an inverted-U shaped relationship between competition and innovation, and the empirical analysis finds evidence for such a relationship. Röller, Siebert and Tombak (2007) analyse incentives to form RJVs by estimating an endogenous switching model using U.S. data. They also construct a theoretical model for RJV formation with asymmetric

\footnotetext{
${ }^{10}$ Related to this is Reinganum (1985) who considers sequential, drastic innovations, and shows that the market at any given time is monopolised by the firm that most recently made the innovation.
} 
firms, but their approach is different to ours in three important aspects in that they only consider a duopoly, firms in an RJV coordinate their investment and share R\&D costs, and finally as a consequence of only considering a duopoly they do not consider endogenous RJV formation. Some of their main empirical findings are that cost-sharing is an important incentive for RJV formation, and that RJVs tend to be formed among firms of similar size. The former effect is absent in the present analysis, and could strengthen the incentives to form RJVs, and the latter is consistent with the theoretical predictions of the present analysis.

The present paper is also related to the literature on the sharing of private cost and demand information in oligopolies, notably Fried (1984), Gal-Or (1985, 1986), Shapiro (1986), Vives (1984), and Okuno-Fujiwara, Postlewaite and Suzumura (1990). Whereas these papers consider the exchange of information in asymmetric information models which affects the firms' perception of the competition, the present analysis is concerned with exchange of information that directly affects the marginal cost of production of the partners to a coalition. The link is, as pointed out by Eaton and Eswaran (1997), that the information that is exchanged is in both cases non-rivalrous. Eaton and Eswaran (1997) show in the context of a supergame that trading of technical information can be sustained as an equilibrium. The mechanism to sustain sharing is through punishments (ejection from the coalition if providing empty information). The trading of technical information may reduce the marginal cost of production for the partners of a coalition in a similar way to the present analysis, but in Eaton and Eswaran (1997) firms have ex ante identical marginal cost of production, which implies that all firms in a coalition have identical marginal cost when all relevant information is traded in the coalition.

The rest of the paper is organized as follows: In section 2 we present the basic model and the non-coalition outcome. In section 3, 4, 5, and 6 we analyze the four possible coalition structures. In section 7 we compare the R\&D investment levels under the different technology sharing coalitions, and in section 8 we endogenise the coalition formation. In section 9 we look at welfare aspects of the different coalitions, in section 10 we look at antitrust policy and research cooperation, in section 11 we consider a case study of aircraft engine manufacturing, and in section 10 we make some concluding remarks. 


\section{The Benchmark Model}

There are three firms 1,2 and 3 who produce a homogeneous product for which the inverse demand function is

$$
p=1-\sum_{i=1}^{3} q_{i}
$$

where $p$ is the product price, and $q_{i}$ is the quantity produced by firm $i=1,2,3$. The initial marginal production cost faced by each firm is $c_{i}=i c$ where $c>0$ and hence gives a direct measure of cost asymmetry in the industry. At stage 1, each firm has the possibility of investing in $\mathrm{R} \& \mathrm{D}$ in order to reduce this marginal cost; the cost of R\&D is the same for each firm: $k\left(x_{i}\right)=\frac{\gamma x_{i}^{2}}{2}$, where $x_{i}$ is the amount of $\mathrm{R} \& \mathrm{D}$ undertaken by firm $i$ and $\gamma$ is a constant parameter. Marginal cost is affected by R\&D in the following way:

$$
\widehat{c_{i}}=i c-x_{i}
$$

where $\widehat{c_{i}}$ is post R\&D cost for firm $i{ }^{11}$ We assume initially that there are no spillovers from one firm's investment to the others. At stage 2 the firms compete in quantities in the product market. The coalition partners operate as a form of RJV in which the partners share their technology advancements perfectly, but they choose both quantity and R\&D spending non-cooperatively. There is no sharing of $R \& D$ costs, and the only effect of a coalition is sharing of improved technology through spillovers which reduces costs of producing the final product. In the

\footnotetext{
${ }^{11}$ In a previous version we have worked with a more general asymmetric situation. In particular, the ex post marginal cost has been formulated as follows: $\widehat{c}_{a}=\theta_{a} c-x_{a}$ for the post R\&D marginal cost without a coalition, and $\hat{c}_{i}^{i j}=\theta_{i} c-x_{i}-x_{j}$ is the post R\&D cost for firm $i$ when in a coalition between firms $i$ and $j$, and $\hat{c}_{k}^{i j}=\theta_{k} c-x_{k}$ is the post R\&D cost for the outsider. Although this is a more general approach, the results with respect to the various technology sharing arrangements do not change qualitatively. In addition, we are not able to solve for the equilibrium coalition, which is an important part of the current paper. Hence, we focus on the simplified approach from the outset.
} 
terminology of Kamien, Muller and Zang (1992) we analyse RJVs with competition. In contrast to the majority of the literature on strategic R\&D investments where there typically are imperfect spillovers between investing firms, we consider a setting with either zero or perfect spillovers. ${ }^{12}$ The introduction of ex ante asymmetric firms, which is not a common feature in models of strategic R\&D investments, necessitates such a simplification of the model to make the model and analysis tractable. One effect of this simplification is that it accentuates the free-rider effect on investment incentives.

The firms that enter into a coalition enjoy perfect spillovers, whereas the outsider can only improve on own costs through his own investments. The R\&D activities of the coalition partners are by the perfect spillover assumption considered as perfectly complementary activities. In a number of different RJVs the R\&D undertaken by partner firms consists of developing either new technologies or adopting existing technologies in different dimensions, although each partner may have capabilities in all relevant dimensions. One example of this, is aircraft engine manufacturing which will be addressed in more detail below, where two of the three major manufacturers formed a joint venture to develop a new engine (the partners are General Electric and Pratt-Whitney). Any new technology developed during the course of this joint project can be utilised in other engine programmes. It is therefore reasonable that there is a spillover effect from the joint venture to other products manufactured by each of the partners. In the semiconductor industry, Gugler and Siebert (2007) find evidence for efficiency gains from forming RJVs. This is in particular true in the microcomponents segment of the industry, where each of the firms participating in the RJV can achieve up to a $15 \%$ increase in its market share. This suggests that there may be a substantial spillover effect on costs by joining a RJV.

We assume the existence of an upper and a lower bound on $c$ in order to ensure existence of equilibrium for each of the market games that we consider: $\bar{c}>c>\underline{c} .{ }^{13}$ The upper bound ensures that each firm is willing to invest in R\&D

\footnotetext{
${ }^{12}$ The seminal paper on strategic R\&D investments is d'Aspremont and Jacquemin (1988). Similar issues are analysed by Suzumura (1992), Leahy and Neary (1997), and Brod and Shivakumar (1997).

${ }^{13}$ These bounds depend upon $\gamma: \bar{c}=\frac{2-\gamma}{6(1-\gamma)}$ and $\underline{c}=\frac{2(2 \gamma-3)}{8 \gamma^{2}-17 \gamma-3}$. This interval is defined for the range of $\gamma>5$ that we consider.
} 
in equilibrium, and the lower bound guarantees that ex post marginal cost is always positive. To be able to focus on endogenous coalition formation, we need at least three active firms. This implies that we need to restrict our attention to interior equilibria. Existence of an interior equilibrium for the different coalition cases hold for different sets of parameter values. In order to be able to make a comparison between the cases, we must take this into account and impose the restrictions that encompass the various equilibria that are investigated. The parameter space which ensures existence for the case in which the most efficient firms cooperate is encompassed by that of all other cases, and hence the equilibria exist collectively for $\bar{c}>c>\underline{c}$. In addition, we need to impose the restriction that $\gamma>5$ to ensure existence of all equilibria we consider.

To determine the sub-game perfect Nash equilibrium of the game we work backwards from stage 2, assuming that the firms act non-cooperatively at each stage. The maximization problem of firm $i$ is

$$
\max _{q_{i}} \pi_{i}=\left(1-\left(q_{i}+q_{j}+q_{k}\right)-i c+x_{i}\right) q_{i}
$$

where $i, j, k=1,2,3, i \neq j \neq k$.

Given the amount of R\&D undertaken at stage 1, the quantity produced by each firm at stage 2 is:

$$
\begin{aligned}
& q_{1}=\frac{\left(1+2 c+3 x_{1}-x_{2}-x_{3}\right)}{4} \\
& q_{2}=\frac{\left(1-2 c+3 x_{2}-x_{1}-x_{3}\right)}{4} \\
& q_{3}=\frac{\left(1-6 c+3 x_{3}-x_{2}-x_{1}\right)}{4}
\end{aligned}
$$

giving firm $i$ a profit of $\pi_{i}=q_{i}^{2}$ in the product market. Firm $i$ thus chooses its amount of R\&D to solve the following problem:

$$
\max _{x_{i}} \Pi_{i}=\pi_{i}-\frac{\gamma x_{i}^{2}}{2} .
$$


The non-cooperative level of $\mathrm{R} \& \mathrm{D}$ by each firm in an interior equilibrium can then be determined to be

$$
\begin{aligned}
& x_{1}=\frac{3(2 \gamma-3+4 \gamma c+3 c)}{(8 \gamma-3)(2 \gamma-3)} \\
& x_{2}=\frac{3(2 \gamma-3-4 \gamma c+2 c)}{(8 \gamma-3)(2 \gamma-3)} \\
& x_{3}=\frac{3(2 \gamma-3-12 \gamma c+9 c)}{(8 \gamma-3)(2 \gamma-3)} \\
& X=x_{1}+x_{2}+x_{3}=\frac{9(1-2 c)}{(8 \gamma-3)}
\end{aligned}
$$

where the second-order condition for each player's maximization and the stability condition is fulfilled for $\gamma>\frac{3}{2}$ which is the case given the general restriction placed on $\gamma$, with $\gamma>5$. Hence the sign of the denominator in (6) is positive. ${ }^{14}$ The first order conditions for the maximization of (5) yield the following relationship between quantity and $\mathrm{R} \& \mathrm{D}$ of firm $i=1,2,3: q_{i}=\frac{2 \gamma}{3} x_{i}$.It is immediately apparent from (4) and (6) that $q_{1}>q_{2}>q_{3}$ and $x_{1}>x_{2}>x_{3}$ so that the most efficient firm at the outset (firm 1) does the most R\&D and produces the most output in the interior equilibrium. This is may appear contrary to the result of Vickers (1986) when considering Cournot with a (single) patent race. However, the catching-up effect that can be observed in his analysis is partly due to the fact that the innovation is not sufficiently substantial, partly due to the fact that only the winner of the patent race in his model achieves a cost reduction, and partly due to the fact that the winner may end up monopolising the market. In the present analysis, we restrict our attention to the case where all firms are active, and in which all firms invest positive amounts in cost-reducing R\&D. Consequently, all firms achieve some level of cost reduction, which implies that the gain from investing more for the $e x$ ante less efficient firm is not as strong as in Vickers (1986). To sum up:

Proposition 1 In the non-cooperative benchmark case, the most efficient firm ex ante undertakes the highest level of $R \& D$, produces the highest level of output

\footnotetext{
${ }^{14}$ On the stability condition in oligopoly models in general see Seade (1980). For their use in R\&D models see Henriques (1990).
} 
and earns the highest level of profit, and the least efficient firm ex ante undertakes the lowest level of $R \& D$ and earns the lowest level of profit in an interior equilibrium.

Substituting (4) and (6) into (5) reveals the total profits for the three firms in this equilibrium as

$$
\Pi_{i}=\frac{\gamma(8 \gamma-9)}{18}\left(x_{i}\right)^{2} \text { for } i=1,2,3
$$

where $\Pi_{1}>\Pi_{2}>\Pi_{3}$ in equilibrium. The proportionality factor $\frac{\gamma(8 \gamma-9)}{18}$ is strictly positive for all permissible values of $\gamma$.

The difference in the R\&D of two firms that are adjacent in terms of cost, say 1 and 2 , is

$$
x_{1}-x_{2}=\frac{3 c}{2 \gamma-3}
$$

so that the difference in $\mathrm{R} \& \mathrm{D}$ is proportional to the difference in ex ante efficiency. ${ }^{15}$ The relationship for the ex post costs of these two firms is consequently:

$$
\widehat{c}_{2}-\widehat{c}_{1}=\left(2 c-x_{2}\right)-\left(c-x_{1}\right)=\frac{2 \gamma c}{2 \gamma-3} \equiv \alpha c
$$

where the proportionality coefficient $\alpha$ is the same for the comparison between adjacent firms 1 and 2, and 2 and 3 . Since $\alpha>1$, there is a larger relative distance between the firms' marginal cost after R\&D takes place.

Corollary 1 The difference in the level of $R \& D$ undertaken is proportional to the difference in ex ante marginal cost of production. This implies that the difference in ex post marginal cost of production increases after $R \& D$ is undertaken.

In the non-cooperative case, $\mathrm{R} \& \mathrm{D}$ serves to exacerbate existing cost differences between the firms.

\footnotetext{
${ }^{15}$ The ex ante difference in costs is $c$.
} 


\section{Technology Sharing between the Most Efficient Firms}

We now suppose that the two most efficient firms, 1 and 2, agree to share the results of their independent R\&D in the form of a technology sharing consortium. Each firm still decides how much to spend on R\&D independently of the others, but 1 and 2 now get the full benefit of each others' advancement. The cost reducing R\&D can be thought of as complementary R\&D. There is, as before, no spillover to or from the outside firm 3 . Hence the ex post marginal production costs of the firms are given by

$$
\begin{aligned}
& \widehat{c}_{1}^{12}=c-x_{1}^{12}-x_{2}^{12} \\
& \widehat{c}_{2}^{12}=2 c-x_{1}^{12}-x_{2}^{12} \\
& \widehat{c}_{3}^{22}=3 c-x_{3}^{12}
\end{aligned}
$$

where $\widehat{c}_{i}^{12}$ indicates the marginal cost post of R\&D expenditures of firm $i=$ $1,2,3$ given that 1 and 2 share technology advancements.

The profit levels of the firms before the R\&D stage are given by

$$
\begin{aligned}
& \Pi_{1}^{12}=\frac{\left(1-3 \widehat{c}_{1}^{12}+\widehat{c}_{2}^{12}+\widehat{c}_{3}^{12}\right)^{2}}{16}-\gamma \frac{x_{1}^{2}}{2} \\
& \Pi_{2}^{12}=\frac{\left(1-3 \widehat{c}_{2}^{12}+\widehat{c}_{1}^{12}+\widehat{c}_{3}^{12}\right)^{2}}{16}-\gamma \frac{x_{2}^{2}}{2} \\
& \Pi_{3}^{12}=\frac{\left(1-3 \widehat{c}_{3}^{12}+\widehat{c}_{2}^{12}+\widehat{c}_{1}^{12}\right)^{2}}{16}-\gamma \frac{x_{3}^{2}}{2}
\end{aligned}
$$

The interior R\&D expenditures in equilibrium are then 


$$
\begin{aligned}
x_{1}^{12} & =\frac{\left(3 c-3 \gamma-4 c \gamma+2 \gamma^{2}+4 c \gamma^{2}\right)}{\gamma\left(8 \gamma^{2}-17 \gamma+6\right)} \\
x_{2}^{12} & =\frac{\left(13 c \gamma-3 \gamma-3 c+2 \gamma^{2}-4 c \gamma^{2}\right)}{\gamma\left(8 \gamma^{2}-17 \gamma+6\right)} \\
x_{3}^{12} & =\frac{3(\gamma-6 c \gamma+6 c-2)}{\left(8 \gamma^{2}-17 \gamma+6\right)}
\end{aligned}
$$

where the denominator in these expressions is positive by the stability condition. ${ }^{16}$

From (11) one can compute that $x_{1}^{12}-x_{2}^{12}=\frac{c}{\gamma}>0$ from which it is apparent that $x_{1}^{12}>x_{2}^{12}$ for all permissible values of $\gamma$. Hence the firm that is most efficient initially will undertake more R\&D than the less efficient partner, but since all technology advancements are shared among the coalition partners the gap in the R\&D levels of the two inside firms is smaller than in the no-coalition case (see (8)).

In all of the coalition cases that we consider, there is a simple relationship between quantities, total profits, and R\&D expenditure in equilibrium. Suppose that two firms (call them $i$ and $j$ ) cooperate on R\&D whilst firm $k$ is outside. Then equilibrium quantities and total profit in equilibrium are easily determined to be:

$$
\begin{aligned}
q_{i}^{i j} & =\gamma x_{i}^{i j} \\
q_{j}^{i j} & =\gamma x_{j}^{i j} \\
q_{k}^{i j} & =\frac{2 \gamma}{3} x_{k}^{i j}
\end{aligned}
$$

\footnotetext{
${ }^{16}$ Stability requires only that $\gamma>1.678$, and this i satisfied for the general restriction we have placed on $\gamma>5$.
} 


$$
\begin{aligned}
& \Pi_{i}^{i j}=\frac{\gamma(2 \gamma-1)}{2}\left(x_{i}^{i j}\right)^{2} \\
& \Pi_{j}^{i j}=\frac{\gamma(2 \gamma-1)}{2}\left(x_{j}^{i j}\right)^{2} \\
& \Pi_{k}^{i j}=\frac{\gamma(8 \gamma-9)}{18}\left(x_{k}^{i j}\right)^{2}
\end{aligned}
$$

The following proposition then follows.

Proposition 2 i) When the two most efficient firms enter into a coalition, the most efficient partner invests more than the less efficient partner. Due to perfect spillover between the partners the difference in ex post marginal costs are lower than the case with no coalition. ii) The coalition partners enjoy a larger efficiency advantage over the outsider. iii) The outsider may, if the proportionality parameter $c$ is sufficiently low and investment cost is sufficiently high, invest more in $R \& D$ than the insiders' individual $R \& D$ investments.

In Figure 1, parameter combinations that satisfy $\bar{c}>c>\underline{c}$ are in the area between $\mathrm{A}$ and $\mathrm{B}$, and this area is divided up into three sub-areas. ${ }^{17}$ Note that $\gamma=5$ is the lowest value of the cost parameter for which all equilibria exist. In the largest of these (I), the ranking of R\&D by each firm is the same as in the benchmark case: $x_{1}^{12}>x_{2}^{12}>x_{3}^{12}>0$. In area $I I$ we have that $x_{1}^{12}>x_{3}^{12}>x_{2}^{12}>0$ whilst in $I I I$ it is the least effective firm (the outsider) that has the most R\&D: $x_{3}^{12}>x_{1}^{12}>x_{2}^{12}>0$.

Since firms 1 and 2 share the results of their R\&D, the relative difference in their efficiency levels is also preserved ex post. The difference in ex post marginal cost for the coalition partners is simply the ex ante difference given by $c$; furthermore, it can be shown that the difference in ex post marginal costs between the coalition partners is lower than in the benchmark case of no coalition. The partner

\footnotetext{
${ }^{17}$ The equations of all curves denoted by letters in figures are given in Appendix 1 .
} 
Economics: The Open-Access, Open-Assessment E-Journal

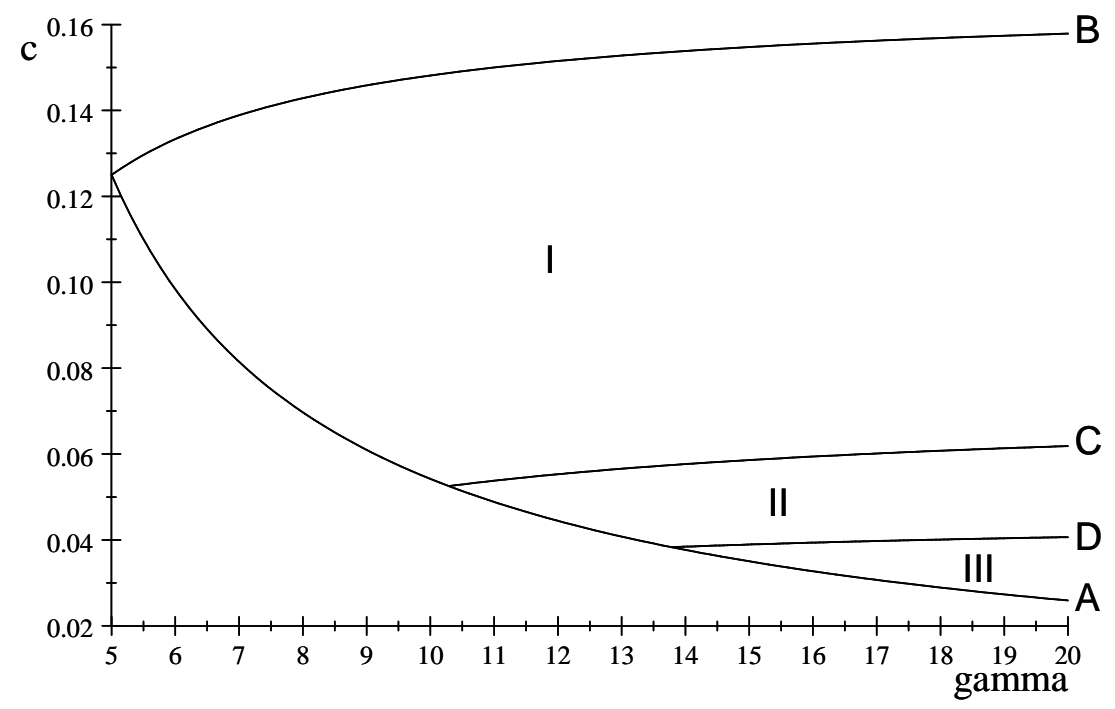

Figure 1: Coalition between the two most efficient firms 
firms manage to gain an additional advantage over the outsider if the sum of their $\mathrm{R} \& \mathrm{D}$ is larger than that of the outsider; i.e., if $x_{i}^{i j}+x_{j}^{i j}>x_{k}^{i j}$ when firms $i$ and $j$ are in a coalition and firm $k$ is the outsider. This is the case in the equilibrium discussed here. Hence, the technology sharing arrangement between the two most efficient firms serves to further disadvantage the less efficient rival. In this respect, this coalition with perfect spillovers tends towards increasing dominance (to use Vickers' terminology). What is also apparent is the fact that the existence of a technology sharing coalition affects the distribution of R\&D across rivals in the industry, and not only the total amount of R\&D.

The intuition behind the results can be explained as follows: The R\&D effort of the two coalition partners are strategic complements due to perfect spillovers, which lead to lower levels of investments for both the partners compared to the no-coalition case (the free-riding effect). Furthermore, since spillovers are perfect and the $R \& D$ costs are convex, the most efficient firm which invests the most in the no-coalition case will face a stronger free-riding effect than the coalition partner and will reduce its investment level more than its partner. This explains why the difference in investment levels between firms 1 and 2 in the no-coalition case is higher than in the coalition case. For the partners, the R\&D effort of the outsider is perceived as a strategic substitute to the partners' effort, and since the coalition partners reduce their overall investment level due to the free-riding effect this implies that the outsider invests more relative to the coalition partners than in the benchmark case. The outsider, in this case firm 3, still invests less than in the no-coalition case, but the difference in investment level relative to the secondmost efficient firm is lower in the coalition case, with $\left(x_{2}^{12}-x_{3}^{12}\right)-\left(x_{2}-x_{3}\right)$ being negative. Although the outsider invests more relative to the coalition partners, which in isolation would tend towards equalisation of the industry, the fact that there are perfect spillovers between the coalition partners implies that the effective cost reduction of the coalition partners is greater than that of the outsider.

If allowing for less than perfect spillovers between the coalition partners, this would ceteris paribus reduce the effective cost reduction and moderate the increasing dominance effect. However, with less than perfect spillovers, the freeriding effect would be less dominant and work in the opposite direction. The overall effect on R\&D activity when considering a more complex model is likely to depend on the degree of product market competition (Aghion et al., 2005), but 
the majority of work in this avenue of research concentrates on total R\&D and not on the distribution of R\&D as in the present paper. What seems to be robust and consistent with empirical findings (Röller et al., 2007), is the fact that firms of equal size are more likely to form RJVs which is essentially what our later equilibrium coalition analysis suggests.

\section{Technology Sharing between the Most and Least Efficient Firms}

Suppose now that firms 1 and 3 join together in the technology sharing arrangement whilst 2 is outside the arrangement. Marginal costs after R\&D are now given by

$$
\begin{aligned}
& \widehat{c}_{1}^{13}=c-x_{1}^{13}-x_{3}^{13} \\
& \widehat{c}_{3}^{13}=3 c-x_{1}^{13}-x_{3}^{13} \\
& \widehat{c}_{2}^{13}=2 c-x_{2}^{13}
\end{aligned}
$$

Equilibrium R\&D levels are

$$
\begin{aligned}
x_{1}^{13} & =\frac{\left(6 c-3 \gamma-11 c \gamma+2 \gamma^{2}+4 c \gamma^{2}\right)}{\gamma\left(8 \gamma^{2}-17 \gamma+6\right)} \\
x_{2}^{13} & =\frac{3(2 c-1)(2-\gamma)}{\left(8 \gamma^{2}-17 \gamma+6\right)} \\
x_{3}^{13} & =\frac{\left(-6 c-3 \gamma+23 c \gamma+2 \gamma^{2}-12 c \gamma^{2}\right)}{\gamma\left(8 \gamma^{2}-17 \gamma+6\right)}
\end{aligned}
$$

and the quantities and profits follow (12) and (13). To sum up:

Proposition 3 i) When the most and the least efficient firms enter into a coalition, the outsider will invest more than the insiders if the proportionality parameter $c$ is sufficiently high. ii) Even with higher investment levels for the outsider, the least efficient firm closes the gap on the outsider. 
The intuition behind these results are essentially the same as described above. The outsider, firm $j$, has stronger incentives to invest in cost reducing $\mathrm{R} \& \mathrm{D}$ than the insiders. This is due to the fact that the insiders face free-riding issues and strategic complementarity between their investments, which reduces their investments and reduces the investment of the ex ante most efficient firm most. Since the insiders' investment and that of the outsider are strategic substitutes, the reduction in the coalition partners' investments results in higher investment by the outsider. The reason why the outsider may, for some parameter values, invest more than the most efficient insider is that for some levels of the initial marginal cost, $c$, the percentage reduction in ex post marginal cost due to $R \& D$ is sufficiently large.

\section{Coalition between the Two Least Efficient Firms}

The final possibility that we consider is one in which the least efficient firms, 2 and 3, agree to share the results of their R\&D, with the most efficient firm outside of the arrangement. Ex post costs are then

$$
\begin{aligned}
& \widehat{c}_{1}^{23}=c-x_{1}^{23} \\
& \widehat{c}_{2}^{23}=2 c-x_{2}^{23}-x_{3}^{23} \\
& \widehat{c}_{3}^{23}=3 c-x_{2}^{23}-x_{3}^{23}
\end{aligned}
$$

with equilibrium R\&D:

$$
\begin{aligned}
x_{1}^{23} & =\frac{3(2 c+\gamma+2 c \gamma-2)}{8 \gamma^{2}-17 \gamma+6} \\
x_{2}^{23} & =\frac{\left(3 c-3 \gamma-c \gamma+2 \gamma^{2}-4 c \gamma^{2}\right)}{\gamma\left(8 \gamma^{2}-17 \gamma+6\right)} \\
x_{3}^{23} & =\frac{\left(16 c \gamma-3 \gamma-3 c+2 \gamma^{2}-12 c \gamma^{2}\right)}{\gamma\left(8 \gamma^{2}-17 \gamma+6\right)}
\end{aligned}
$$

Again, equilibrium quantities and profits follow the pattern in (12) and (13), the following result is easily verified. 
Proposition 4 i) When the two least efficient firms enter into a coalition, the ex ante most efficient firm undertakes the highest level of $R \& D$ and the ex ante least efficient firm provides the lowest level of $R \& D$. ii) If the proportionality parameter $c$ is sufficiently high, and above $\gamma /(22 \gamma-9)$, the gap in ex post efficiency between the coalition partners and the efficient outsider becomes larger. iii) If $c$ is below this level, the coalition partners will gain relative to the efficient outsider, but will not catch up completely.

\section{The Three-Firm Coalition}

The final possibility is a grand coalition involving all three firms. In this case ex post costs are

$$
\begin{aligned}
& \widehat{c}_{1}^{123}=c-X^{123} \\
& \widehat{c}_{2}^{123}=2 c-X^{123} \\
& \widehat{c}_{3}^{123}=3 c-X^{123}
\end{aligned}
$$

where $X^{123}=x_{1}^{123}+x_{2}^{123}+x_{3}^{123}$, with equilibrium R\&D:

$$
\begin{aligned}
x_{1}^{123} & =\frac{-3 c+2 \gamma+4 c \gamma}{2 \gamma(8 \gamma-3)} \\
x_{2}^{123} & =\frac{1-2 c}{8 \gamma-3} \\
x_{3}^{123} & =\frac{3 c+2 \gamma-12 c \gamma}{2 \gamma(8 \gamma-3)}
\end{aligned}
$$

The total level of $\mathrm{R} \& \mathrm{D}$ in this case is $X^{123}=\frac{3(1-2 c)}{8 \gamma-3}$, which is one third of the total non-cooperative R\&D from equation (6). Since all three firms participate in the coalition, there is no change in the relative competitiveness. Although all three firms participate both the level of R\&D and the output decisions are still taken independently. From Bergstrom and Varian (1985) we know that the Nash outcome of a class of games will be independent of the distribution of the firms' characteristics. The total output in the final stage is independent of the individual firm's ex post marginal cost and depends only on the sum of the firms' ex post 
marginal costs, since $Q=\left(3-\left(\widehat{c}_{1}+\widehat{c}_{2}+\widehat{c}_{3}\right)\right) / 4$. This implies that it is not the total $\mathrm{R} \& \mathrm{D}$ effort that matters, but the effective reduction in the sum of marginal costs that results from the R\&D activities. Since there are perfect spillovers within a coalition which adds to the benefit of $R \& D$, the effective reduction in marginal costs will depend on whether there is a coalition and which firms enter into a technology sharing coalition. In the case of the grand coalition the effective reduction in a given firm's ex post marginal cost is $\left(x_{1}^{123}+x_{2}^{123}+x_{3}^{123}\right)$. In this case the freeriding effect on each individual firm's $\mathrm{R} \& \mathrm{D}$ incentives is such that the reduction in ex post marginal cost with the grand coalition and with no coalition is effectively identical. Even if total R\&D is lower the effective cost reduction for the coalition members is high. The implication of this is that total output in the two structures are identical, and that consumers are indifferent between no coalition and the grand coalition.

\section{Comparison of R\&D Levels}

In this section we look at the relative properties of the four cases considered. One can determine that the relationship between the total amounts of R\&D undertaken is given by $X>X^{23}>X^{13}>X^{12}>X^{123}$. For the most efficient firm we find that $x_{1}>x_{1}^{23}>x_{1}^{12}>x_{1}^{13}>x_{1}^{123}$ so that it undertakes the most R\&D in the stand-alone situation, and the least amount when all three firms enter into a coalition. Of the cooperative solutions it conducts most R\&D as an outsider to a technology sharing partnership. For the intermediate firm the comparison is also straightforward: $x_{2}>x_{2}^{13}>x_{2}^{13}>x_{2}^{13}>x_{2}^{123}$. For the least efficient firm the comparison is partly parameter specific. It is, however, unambiguously the case that $x_{3}>x_{3}^{12}, x_{3}^{13}>x_{3}^{23}$, and $x_{3}^{123}<x_{3}^{23}$. Furthermore when $c$ is sufficiently large ${ }^{18}$ then $x_{3}^{12}>x_{3}^{13}$.

To sum up:

Proposition 5 i) The total level of $R \& D$ is highest when there is no coalition, lowest of the two-firm coalitions when the two most efficient firms enter into a coalition, and lowest overall in the grand coalition: $X>X^{23}>X^{13}>X^{12}>X^{123}$.

\footnotetext{
${ }^{18}$ Specifically $c>\frac{\gamma(\gamma-3)}{6 \gamma^{2}+5 \gamma-6}$.
} 
ii) For the two most efficient firms, the level of $R \& D$ at firm level is higher as an outsider than as an insider.

The level of the ex ante cost difference, $c$, plays an important role in the analysis as it is a measure of the asymmetry between the firms. The comparative static results for R\&D expenditures show that the equilibrium level of investment is affected by an increase in $c$ in the following way:

$$
\begin{aligned}
& \frac{\partial x_{1}^{h}}{\partial c}>0 \\
& \frac{\partial x_{2}^{h}}{\partial c}<0 \\
& \frac{\partial x_{3}^{h}}{\partial c}<0
\end{aligned}
$$

for all $h$, where $h$ denotes the type of coalition; $h=\{12,13,23,123\}$. Thus, the most efficient firm will in all of the coalition cases increase expenditure on R\&D when the ex ante cost difference increases. This is also the case when firms operate without technology sharing arrangements. Since both quantity and profits are proportional to $\mathrm{R} \& \mathrm{D}$ expenditure, the comparative statics with respect to changes in $c$ will have the same signs as (18). The reason for this seemingly counterintuitive comparative statics results is due to the fact that when $c$ increases firms become more asymmetric ex ante, and our specification of the asymmetry between firms implies that for each unit of increase in $c$ the marginal cost of firm 2 increases two-fold and for firm 3 the increase is three-fold. This implies that ex ante most efficient firm enjoys a substantially larger percentage reduction in ex post marginal cost from any given R\&D investment, and hence the results in (18).

\section{Equilibrium Technology Sharing Arrangement}

In order to establish which, if any, technology sharing arrangement would arise endogenously, we need a solution concept that ensures both that each individual coalition partner is at least as well of in the coalition as the best alternative outcome, and that no outside firm can break the coalition. To break a coalition, the 
breaking firm must be able to offer a more attractive prospect to one of the coalition partners than is achieved as part of the coalition. A given firm can offer to another firm any share of the profit it gains from entering into a particular agreement. Each firm is restricted only by its own participation constraint, and any side payment it deems necessary is allowed. The equilibrium coalition is a coalition which is both internally and externally stable. This means that in equilibrium no outsider finds it profitable to offer an alternative deal to one of the insiders to break the coalition, and the insiders earn at least the level of profit as in the best alternative coalition. If one of the coalition partners leaves the coalition, then the coalition breaks down and may be replaced with another coalition. In our setting with only three players, a two firm coalition will naturally break up if one of the firms depart and we are back in the no coalition scenario.

A coalition $C^{i}$ is said to dominate another coalition $C^{j}$ if the combined profit of the decisive coalition partners is larger in $C^{i}$ than in $C^{j}$. A decisive partner is able to influence which of the coalitions will be formed. In comparing any twofirm coalition with another two-firm coalition, all three firms are decisive. Let us consider, for example, the coalition consisting of firms 1 and $2\left(C^{12}\right)$, with a coalition consisting of firms 2 and $3\left(C^{23}\right)$. All firms are decisive. The reason being that if firm 3 is sufficiently adversely affected by a coalition between 1 and 2 , then firm 3 may attempt to persuade firm 2, to enter into a coalition with 3 and break the coalition between 1 and 2, by offering firm 2 a larger share than it receives in $C^{12}$. A similar argument can be made for the other constellations. When comparing any two-firm coalition with the default outcome of no coalition, the outsider is no longer decisive. To find the structure that dominates involves comparing the sum of the two coalition partners' profit in the coalition with the sum of their profits without a coalition. ${ }^{19}$ The coalition structures that are undominated are the equilibrium technology sharing arrangements.

This implies that the arrangement that yields the highest level of industry profit will be the chosen coalition, provided that this structure awards the coalition partners higher profit than the default outcome; i.e., the sum of profit for the coalition partners in the absence of a technology sharing arrangement. This ensures that

\footnotetext{
${ }^{19}$ See Horn and Persson (2001) or Straume (2006) for more detailed explanations. Horn and Persson (2001) generalises the equilibrium coalition structure to $\mathrm{n}$ player.
} 
conomics: The Open-Access, Open-Assessment E-Journal

the coalition cannot be broken by an offer from an outsider, and that the partners would enter the coalition voluntarily given the status quo represented by the initial situation. In this section we find the main result of the paper:

Proposition 6 i) When considering two-firm coalitions only, the endogenously determined equilibrium technology sharing coalition consists of the two most efficient firms entering into a coalition. ii) If allowing for a three-firm coalition, then the endogenously determined equilibrium coalition comprises all three firms only when the ex ante marginal cost, $c$, is sufficiently low. If $c$ is above this threshold, then the coalition comprising the two most efficient firms is the equilibrium coalition.

\section{Proof: See Appendix 2.}

Figure 2 delineates the parameter values that are consistent with the two equilibrium coalition structures. For parameter values between lines $\mathrm{A}$ and $\mathrm{H}$, the three-firm coalition $C^{123}$ dominates all other coalitions, whereas between lines $\mathrm{B}$ and $\mathrm{H}$ the two-firm coalition comprising firms 1 and $2, C^{12}$, dominates. ${ }^{20}$ When ex ante marginal costs are low, the potential for innovation is limited. In such a situation the investing firms realise that it makes sense to invest less than in a situation where the potential for innovation is greater. The coalition structure that implies the lowest overall R\&D is the three-firm coalition. The investment level of each individual firm is unambiguously lower for firms 1 and 2, but not necessarily for firm 3. The perfect spillover of R\&D between firms implies that this structure achieves a given reduction in marginal production cost with the lowest effort.

The idea behind the equilibrium concept utilised here is that no single firm or coalition of firms can break up the coalition, and each of the firms within the coalition is at least as well of within the coalition as being outsiders. The incentive to be an outsider to a merger is well known in the literature, with seminal contributions from Stiegler (1950), Farrell and Shapiro (1990) under Cournot competition, and Deneckere and Davidson (1985) with Bertrand competition. With Cournot competition, outsiders tend to profit more from a merger than insiders if there are no

\footnotetext{
${ }^{20}$ In Figure 2, we have used $C^{h}$ to indicate that the coalition of type $h$ forms delineated by different cases.
} 
conomics: The Open-Access, Open-Assessment E-Journal

synergy effects. The seminal contribution is Salant, Switzer and Reynolds (1983). With sufficient synergy effects prices might fall, but the contraction in output by the insiders will always trigger an increase in the output by the outsider(s) which on its own is a benefit for the outsiders. Although we do not consider mergers in the product market in the present analysis, an RJV coalition yields efficiency (synergy) effects in the product market. In the present analysis the coalition partners are at least as well of within the coalition as outside and the market share of the coalition partners increases vis a vis the no coalition case due to significant efficiency effects, which is similar to Farrell and Shapiro (1990) with synergy effects. The overall effect of the equilibrium coalition is to reduce price. Consequently, the R\&D coalition both increases production efficiency and results in a lower price, which leads us to conclude that consumers are also better off with than without this coalition.

From Figure 2 it is also apparent that the level of the ex ante marginal cost, $c$, plays an important role when determining which of the coalitions that will emerge in equilibrium. The parameter $c$ is also a measure of the degree of asymmetry between firms, and we observe that for a low degree of asymmetry (low $c$ ) the equilibrium coalition is the grand coalition, whereas with high degree of asymmetry the equilibrium coalition is the coalition of the two most efficient firms. Contrary to the result in Röller et al. (2007), industry profit is not necessarily lower with the formation of a technology sharing coalition. The equilibrium coalition only emerges if this is a more beneficial arrangement for all partners than the best alternative arrangement.

\section{Welfare Comparison and Discussion}

The outcome of a process of endogenous coalition formation has been shown to be technology sharing either between the two most efficient firms, or between all three firms. We now consider the effects that this will have on the product market equilibrium and consumer surplus in this market.

We have shown above that of the coalition outcomes involving two partners, the industry profit is highest when the two most efficient firms enter into a tech- 
Economics: The Open-Access, Open-Assessment E-Journal

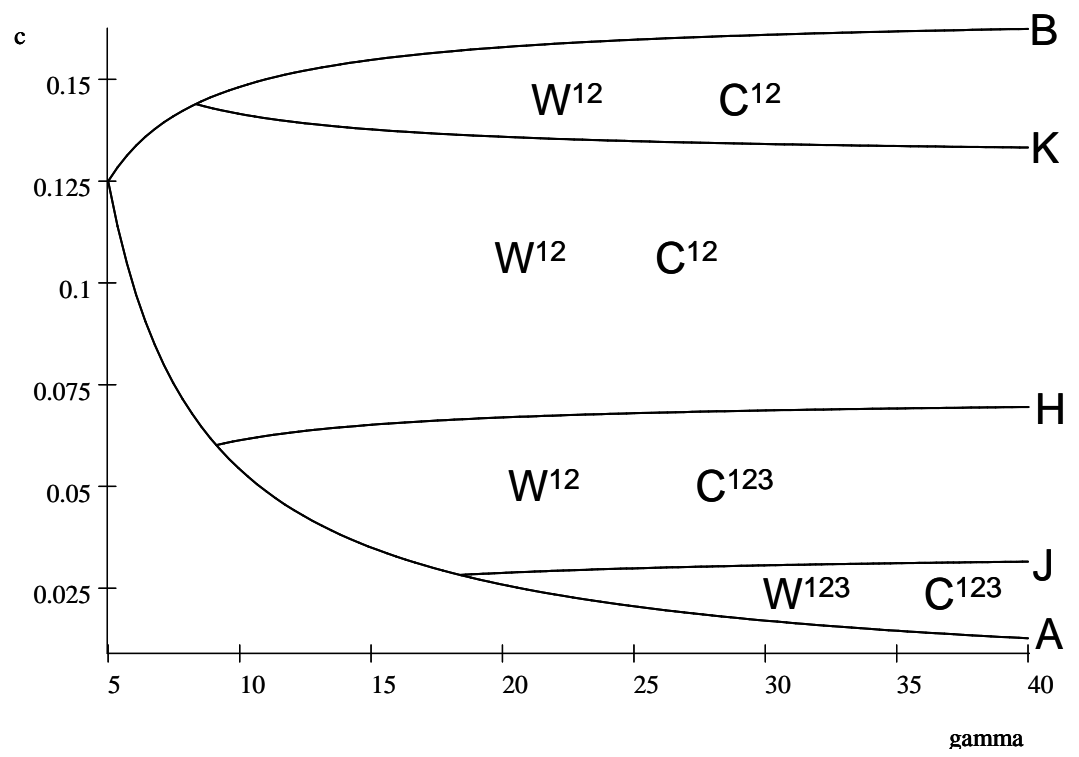

Figure 2: Equilibrium Coalition Structures and Welfare Comparison 
nology sharing consortium, with $\Pi^{12}$ being strictly larger than $\Pi^{13}$ and $\Pi^{23}$ (see (23) and (24) in Appendix 2). It can also be shown that the industry profit without coalitions is strictly lower than the equilibrium coalition, since $\Pi^{12}>\Pi$ where $\Pi=\Pi_{1}+\Pi_{2}+\Pi_{3}$ represents the non-cooperative case. Furthermore, it can be shown that $\Pi^{23}>\Pi$, but $\Pi^{13}$ may be either higher or lower than $\Pi$. However, if (22) in Appendix 2 is violated with $c<\widetilde{c}$, then we know that $\Pi^{12}>\Pi^{13}>\Pi^{23}>\Pi$ with industry profit in the equilibrium coalition being the highest of the potential outcomes considered.

It is also easily shown that consumers' surplus, given by $C S^{i j}=\left(Q^{i j}\right)^{2} / 2$, has the following ranking (for all $c$ and $\gamma$ ):

$$
C S^{12}>C S^{13}>C S^{23}>C S=C S^{123}
$$

Consequently, when $c<\widetilde{c}$ (this is the area between lines $\mathrm{K}$ and $\mathrm{A}$ in Figure 2) the ranking of welfare is given by :

$$
W^{12}>W^{13}>W^{23}>W
$$

where $W^{i j} \equiv C S^{i j}+\Pi^{i j}{ }^{21}$ If considering the three-firm coalition it can be shown that for low ex ante marginal costs it becomes more likely that welfare in the threefirm coalition is higher than the best alternative (the coalition between firms 1 and 2) as $\gamma$ increases (see Figure 2; for parameter values between lines $A$ and $J$ we have $W^{123}>W^{12}$ ). When $c>\widetilde{c}$, welfare is highest when the two most efficient firms are allowed to share technology advancements, since consumers value this coalition highest and the industry profit in this coalition is highest; $W^{12}>W$, and it is also easily shown that $W^{23}>W$. A complete welfare ranking in this case will be parameter specific. This is summed up in the following proposition.

Proposition 7 i) Consumers prefer a coalition between the two ex ante most efficient firms to any other arrangement: $C S^{12}>C S^{13}>C S^{23}>C S=C S^{123}$. ii) When the proportionality parameter $c$ is below a threshold level $\widetilde{c}$, the ranking in terms of welfare is identical to the consumers' surplus ranking. iii) For the threefirm coalition, the free-riding effect dominates the technology advancement effect,

\footnotetext{
${ }^{21}$ In Figure 2, $W^{h}$ indicates that it is coalition $h$ that maximizes welfare in each delineated area.
} 
and consumers are indifferent between a grand coalition and no coalition with $C S=C S^{123}$. iv) For sufficiently low ex ante costs and sufficiently high investment cost, $W^{123}>W^{12}$.

In the context of the present model, we observe that there are no conflicting interests between consumers and firms in terms of which two-firm coalition outcome is preferred provided that the ex ante difference between firms, $c$, satisfies $c<\widetilde{c}$. However, when ex ante marginal cost becomes sufficiently low and $\gamma$ sufficiently large, then firms and consumers have conflicting interests. The three-firm coalition is the least preferred coalition for consumers, but firms prefer this solution when the potential for innovation is limited and the cost of investment high. In such a situation the resulting market output is lower than all two-firm coalitions to the detriment of consumers, but the savings in terms of lower cost of investment for firms outweighs the reduction in consumers' surplus. The result of no conflict when comparing all two-firm coalitions is, perhaps, surprising since one hypothesis might be that higher levels of R\&D lead to higher consumers' surplus and welfare, and we know that the total level of R\&D is in fact lowest with a coalition between firms 1 and 2. The ranking is a consequence of total output being $Q^{12}>Q^{13}>Q^{23}>Q=Q^{123}$ which is inversely related to total $\mathrm{R} \& \mathrm{D}$. The difference between total output in the three potential coalition outcomes is proportional to the parameters $c$ and $\gamma$, with $Q^{12}-Q^{13}=\gamma_{c}$ and $Q^{13}-Q^{23}=\gamma_{c}$. We need to look at other factors to explain why consumers (together with firms and welfare maximizing authorities) prefer the outcome with the lowest level of R\&D expenditure. The possible conflict between the coalition structure that maximizes welfare, and the coalition that will arise endogenously is outlined in Figure 2 as the area between curves $\mathrm{H}$ and $\mathrm{J}$.

In Figure 2, we see a demonstration of the point made by Belleflamme (2000) that the grand coalition will not necessarily arise when firms are asymmetric. In our analysis, it may arise for some parameter values, and for a smaller set of values it will also be welfare optimal.

As is discussed above we know from Bergstrom and Varian (1985) that the Nash outcome of a class of games will be independent of the distribution of the firms' characteristics, and that it is not the total R\&D effort that matters but the effective reduction in the sum of marginal costs resulting from R\&D. In the present 
analysis with perfect spillovers within the coalition, the effective reduction in marginal costs will depend on whether there is a coalition and which firms enter into the coalition. The effective reduction in the case of no coalition is simply given by total R\&D, $X$, and $2\left(x_{i}^{i j}+x_{j}^{i j}\right)+x_{k}^{i j}$ in the case of a coalition between firms $i$ and $j$, where firm $k$ is the outsider. It can easily be shown that the effective reduction in the sum of marginal costs is highest when firms 1 and 2 enter into a coalition, and that the rest of the potential outcomes confirms the consumers' surplus ranking. Consequently, even if the total level of R\&D is lower in all of the three potential coalitions the fact that each unit of R\&D undertaken by the coalition partners effectively counts twice.

\section{Antitrust Policy and Research Joint Ventures}

Article 81 of the EC Treaty states that all agreements between undertakings that may affect trade between member countries, and which may distort, restrict or prevent competition within the common market is prohibited. There are exceptions, notably in terms of block exemptions, for practices that are deemed to be desirable. These are practices "...which contributes to improving the production or distribution of goods or to promoting technical or economic progress, while allowing consumers a fair share of the resulting benefit" (Article 81(3) of the Treaty). The block exemptions come with conditions attached, and should not impose restrictions on the cooperation partners that are not indispensable to the attainment of the objectives (Article 81(3a)), and should not put the partners in a position to be able to eliminate competition "for a substantial part of the products in question" (Article 81(3b)). In the U.S., the National Cooperative Research Act of 1984 enables firms to participate in joint research and development ventures.

Relevant to the present analysis is the Commission Regulation (EC) No 2659/2000 of 29th November 2000 on the application of Article 81(3) of the Treaty to categories of research and development agreements. In paragraph (14) of this regulation it is stated that "..to justify the exemption, the joint exploitation should relate to product and processes for which the use of the results of the research and development is decisive, and each of the parties is given the opportunity of exploiting any results that interest it". The implication of this is that the R\&D 
undertaken affects either the product or the (production) processes, which would not have happened in the absence of the cooperative effort. The other implication is that the development of new processes, which may result in, e.g., lower production costs, should be allowed to be utilised by any of the parties to the cooperation. Put differently, if the outcome of the cooperation is successful, the benefit introduces a spillover effect on either (production) costs or product attributes. This is of importance to our analysis, since we assume that there is spillover from the R\&D process to production costs.

To ensure that the block exemption does not hinder effective competition, there is a market share limitation on the partners' combined market share in the market for products arising from the joint research and development cooperation. The market share restriction (and restrictions on the length of the exemption) is specified in Commission Regulation No 2659/2000, Article 4. If the participating firms are competitors, the exemption requires that the combined market share of the partners does not exceed $25 \%$ in the relevant market. However, a market share of more than $25 \%$ does not necessarily imply an infringement of Article 81(1), and a research and development joint venture with a larger market share may still pass the examination of competition authorities. Imposing such a requirement to exempt the coalition from antitrust action can be seen as an extra restriction on the optimisation problem. We will discuss the effect of a restriction on market shares briefly below, without formally incorporating such a constraint in the optimisation problem.

In the setting of our model with only three active firms, it is naturally unlikely that this constraint can be met in many of the coalitions we consider. The market shares for each of the three firms, $s_{i}$ for $i=1,2,3$, operating as independent firms and prior to any cost reducing investments are given by:

$$
\begin{aligned}
& s_{1}=\frac{q_{1}}{Q}=\frac{1}{3}\left(\frac{3 c+1}{1-2 c}\right) \\
& s_{2}=\frac{q_{2}}{Q}=\frac{1}{3}\left(\frac{1}{1-2 c}\right) \\
& s_{3}=\frac{q_{3}}{Q}=\frac{1}{3}\left(\frac{1-3 c}{1-2 c}\right)
\end{aligned}
$$


where both $s_{1}$ and $s_{2}$ are increasing functions of $c$, whereas $s_{3}$ is a decreasing function of $c$. When all three firms are symmetric $(c=0)$ they each have a market share of $1 / 3$. Taking into account the equilibrium cost reducing investments for the three firms operating independently shows a similar picture. Naturally, the grand coalition will be ruled out by the market share restriction. Investigating the market share of the three two-firm coalitions, there is only one coalition that appears to be close to be within the market share restriction posed by Commission Regulation No 2659/2000. The coalition between the two most efficient firms, which is one of the two equilibrium coalition structures that emerge, has a minimum market share of $2 / 3$ and is increasing in $c$ and decreasing in $\gamma$. Consequently, the antitrust guidelines for cooperative research and development in the EU indicate that the two equilibrium structures will be prohibited, or will at least not fall within the block exemption. Since the coalition between the two most efficient firms is the preferred coalition, both as seen from an industry, consumer surplus and welfare maximising perspective, the guidelines do not appear to improve welfare. The only coalition that comes close to satisfying the market share restrictions, is the coalition between the two least efficient firms, although for the parameter space we consider $(\bar{c}>c>\underline{c}$, and $\gamma>5)$ the market share of this coalition will exceed $25 \%$, but may be below $30 \%$. If the degree of asymmetry between the firms is large, i.e., $c$ is large, and the cost of undertaking cost reducing R\&D investments is sufficiently high, then the market share of the coalition between firms 2 and 3 may come close to the $25 \%$ market share requirement.

\section{A Case Study: Aircraft Engine Manufacturing}

In the manufacturing of aircraft engines for medium narrowbody (Boeing B737series, Airbus A320-series) and widebody aircraft (A330/340, A380, B767, B777, $\mathrm{B} 747)$, there are three firms that dominate the market. The three firms are General Electric Aviation (GE), Pratt-Whitney (PW), and Rolls-Royce (RR). These firms operate both as independent manufacturers, and (to varying degrees) as part of joint ventures. We do not have access to official data on engine deliveries, but based on a rough estimate of engine deliveries based on delivery data for narrowbody and widebody jets for Boeing and Airbus for 2008 the market shares for 
these three producers are: ${ }^{22}$ GE 67\%, RR 19\%, and PW 14\%. Some of these aircraft are fitted with an engine that is a result of a joint venture between GE and Snecma (CFM-engines that power Boeing B737-models, and approximately 50\% of Airbus A320-models). Snecma is not a stand-alone producer, and following EU Commission's analysis for the proposed GE/Honeywell-merger CFM-engines are characterised as GE products for market share purposes. ${ }^{23}$ Similarly, a joint venture between RR and PW (and others) produces an alternative engine for the Airbus A320-series, the IAE2500. The market share of IAE is split 50-50 between RR and PW. In addition to market shares for new deliveries, it would be beneficial to have market share information on installed base of engines. Due to engine commonality, there are benefits for airlines of operating with similar engine types. This is information that we do not have access to, but Giotakos et al. (2001) refer to GE as being by far the largest both in terms of installed base and order backlogs for large commercial aircraft, and that GE has experienced the highest growth in installed base.

We do not have access to cost or price data for engines, but it is reasonable to expect that there are at least some degree of both economies of scale and scope in engine production. Engine commonality, in addition to benefits for the airlines, implies that innovations made in one engine can be utilised in other engines which has implications for the production cost for the engine manufacturers. Consequently, it may be reasonable to expect that a large producer, both in terms of large market share within a single engine category and through a number of engine variants, enjoys a cost advantage. In our model, such cost asymmetry is an important feature.

Since engines powering narrowbody and widebody aircraft are not necessarily identical, let us consider splitting market share data into the two categories narrowbody and widebody (2008 deliveries): GE has approximately $70 \%$ of the narrowbody market (through CFM), whereas IAE takes the remaining 30\% (i.e., $15 \%$ of the narrowbody market for RR and $15 \%$ for PW). For widebody, GE on its own products has approximately $53 \%$ of the market (mostly GE90 and CF6), RR around 32\% (mostly Trent 500, 700 and 900), PW around 12\% (PW4000), CFM

\footnotetext{
${ }^{22}$ Source: www.airliners.net.

${ }^{23}$ See, e.g., Giotakos et al. (2001).
} 
around 2\% (joint venture between GE and Snecma) and Engine Alliance (joint venture between GE and PW) around 1\%. Consequently, for widebody aircraft the three major engine manufacturers produce both a product on their own, and two of the three also as part of a joint venture with one of the other manufacturers. In addition to the economies of scale and scope argument, Giotakos et al. (2001) argue that GE, due to its substantial involvement in the financial service sector, is in a position to increase rivals' funding costs through the use of huge discounts when selling in the engine. To be able to match such discounts, rival firms must rely more on external financing than GE which may increase both borrowing cost and the risk that rivals face.

In 1996, two of the three main engine manufacturers, GE and PW, formed the Engine Alliance (EA), and were in 1999 granted exemption from Article 81 of the EC Treaty. ${ }^{24}$ The aim was to produce a new engine for the stretched version of the Boeing 747 which eventually did not materialise, and then subsequently to provide engines for the Airbus' A380-program. The major competitor to the engine developed by EA is manufactured by the third main engine manufacturer, Rolls-Royce (RR Trent 900). Although both GE and PW are fully capable of manufacturing fully functional engines, they intended to combine their complementary technologies. ${ }^{25}$ The GP7200 engine developed by GE and PW combines low pressure turbine and compressor from PW, with high pressure turbine and compressor from GE. Consequently, the effort of the two joint venture partners are complementary. The agreement between the two companies specify that any technology developed in the course this particular engine programme can be used in any other engine programme. It is therefore reasonable to assume that the joint venture between GE and PW may yield efficiency gains also for other engine programmes.

Although we cannot identify cost asymmetries in the production of aircraft engines between the three producers, it is reasonable to expect some degree of asymmetry due to the size difference between the major manufacturers. So we have three asymmetric firms, at least two different joint ventures in the develop-

\footnotetext{
${ }^{24}$ See Commission Decision of 14 September 1999 relating to a proceeding pursuant to Article 81 of the EC Treaty (Case IV/36.213/F2 - GEAE/P\&W). The exemption is until 26 September 2011.

${ }^{25}$ See paragraph (71) in Commission Decision of 14 September 1999 relating to a proceeding pursuant to Article 81 of the EC Treaty (Case IV/36.213/F2 - GEAE/P\&W).
} 
ment and manufacturing of widebody aircraft engines with subsequent (potential) spillovers to other engine programmes. From the analysis above, we predict as the equilibrium outcome either a joint venture between all three firms (the grand coalition) or between the two most efficient firms. If we take market share as an indication of efficiency (e.g., due to economies of scale and scope), GE is the most efficient firm, then RR, and finally PW. Our theoretical model consequently predicts either all firms, or GE and RR, form a joint venture. This is not something we observe. However, from the section above we have also learnt that the exemption from Article 81 in the EC Treaty for R\&D cooperation puts restrictions on market share for the partners. In the widebody market, GE and RR are by far the two dominant firms with a total market share of around $85 \%$ with engines produced solely by GE and RR, respectively. Consequently, it is very unlikely that antitrust exemption would be granted for a research joint venture between these two firms. A joint venture between GE and PW would command a market share for widebody engines of around $65 \%$, which is also above the threshold level of $25 \%$. What should be noted is that the $25 \%$ threshold level is applicable for block exemption, and a joint venture with larger market share may be approved if it is deemed not to infringe Article 81(1) of the EC Treaty. In this case, allowing the EA joint venture facilitated the development and production of the only alternative to the RR engine for the A380-series.

Circumstantial evidence, based on a comparison of market shares in aircraft engine manufacturing, indicates that the proposed solutions from the theoretical model seem not to be implementable. It is likely that this is mainly due to a concern that allowing GE and RR to form a joint venture could have a too large negative effect on competition, and would essentially monopolise the market for engines suitable for very large widebody aircraft. Although the third firm, PW, currently offers an engine option for the B747-400 which is the closest aircraft to the A380 in terms of passenger capacity, the next generation B747 will not be offered with a PW engine option. PW would then be out of this market segment. Although not the same size as the A380, the largest version of the A340 (the A340-600) is comparable in passenger capacity to the B747-400, and is powered by RR Trent 500 engines. Thus, PW seems to become a minor player in the market for large widebody aircraft in the future without the involvement with GE in the 
conomics: The Open-Access, Open-Assessment E-Journal

Engine Alliance. It is not unlikely that this played an important role in granting the joint venture between GE and PW exemption from Article 81 in the EC Treaty.

\section{Concluding Remarks}

In this paper we have addressed the issue of cooperation in R\&D strategy between heterogeneous firms by allowing endogenous technology sharing. Neither heterogeneity between firms nor endogenous cooperation structures have been fully explored in the R\&D literature. To facilitate this analysis we have thus had to limit the analysis to a particular kind of asymmetry between the firms. Nevertheless, the results are indicative of the sort of pitfalls that can be faced by industrial policy makers in attempting to reach and ambitious R\&D target. In our model, when the two most efficient firms join together and share technological breakthroughs, it is not possible for the outsider to offer either of the partners a better deal when considering only two-firm coalitions. In addition the partners prefer sharing their technology over the initial non-cooperative situation. Hence this is one of the two technology sharing agreement that will be predicted to arise endogenously. For sufficiently low ex ante marginal cost, the three-firm coalition will dominate all other coalitions and will emerge as the equilibrium structure. Moreover, we have shown that when the coalition between the two most efficient firms is the equilibrium, this agreement also maximizes the total welfare in society. The three-firm coalition may emerge as the equilibrium structure, but will for certain parameter combinations be welfare sub-optimal. Both these structures that may arise in equilibrium give the overall lowest amount of R\&D. However, as is pointed out above it is not necessarily the total amount of R\&D that is of importance when ascertaining the welfare effect of a particular coalition, but the distribution of R\&D effort across firms.

The only commitment a coalition makes is to share technology improvements with the other coalition members, and there is no coordination of R\&D efforts by the firms. Consequently, the issue we analyse is a pure technology sharing agreement rather than $\mathrm{R} \& \mathrm{D}$ cooperation per se. Our approach is identical to the approach coined "RJV competition" in Kamien, Muller and Zang (1992). Although not representative for all types of $R \& D$ cooperation, we argue that our approach is 
compatible with a number of technology sharing arrangements, among them the aircraft engine manufacturing example provided in the paper.

In the present analysis, technology sharing affects variable costs. If technology sharing were to affect fixed costs, this would have potential impact through at least two different channels. First, fixed costs would affect entry/exit decisions by firms. Since we consider only equilibria in which all three firms are active this is not an issue here. Second, changes to fixed costs will affect the difference in insider and outsider profits. This may affect the incentives for the outsider to break an existing coalition by offering one of the coalition partners a more attractive deal. However, the cost savings from entering into a coalition in our approach also affects the difference between outsider and insider profits (and the incentives to break the coalition). Since the endogenously chosen coalition is one which yields the highest industry profit, the result from our approach is likely to be (qualitatively) similar to a setting where coalitions affect fixed costs. Horn \& Persson (2001) state that with fixed cost savings the set of equilibrium coalitions are the structures with minimal industry cost.

In the above analysis, we have implicitly assumed that all firms are equally capable of utilising the technology advancements. It is not unreasonable to assume that the absorptive capacity of firms may differ, and the degree of absorption of technology improvements may depend on the initial technology. This initial technology may, of course, be the result of an endogenous choice. Differences in absorptive capacity may be reflected through firm specific and imperfect spillover parameters.

In terms of the welfare ranking of the outcomes, we have seen that the virtue of perfect spillover is to add additional benefit to a coalition by in essence double the impact of any R\&D undertaken by firms in a coalition. If the coalition partners enjoy less than perfect spillovers, then the results with respect to the welfare ranking could be changed. In addition, free-riding becomes less of a problem. This is, in particular, the case with spillovers close to zero. In such a case, the value for society in terms of added consumers' surplus of allowing a coalition is low. Nevertheless, if the coalition is costless for a participating firm it may still choose to agree to such a coalition even with very low spillovers, provided that the cost advantage of the firm over its rivals is not deteriorated. 
Our analysis is restricted to only three firms, which rules out more fragmented situations than a triopoly. In this respect, the present analysis represents highly concentrated industries, such as our aircraft engine manufacturing example. In less concentrated industries, there might be more than one decisive group which may have an impact on the analysis of the equilibrium coalition structure, and it is thus reasonable to expect that the results will not be as strong. This is acknowledged in Horn \& Persson (2001), in which they state that "it is difficult to derive results as strong as those in Propositions 1 and 2 for less concentrated structures, because of the intransitivity of the dominance relation". Furthermore, our solution concept for the endogenous coalition follows the strand of literature which allows potential partners to communicate freely and to sign binding contracts. In the alternative, non-cooperative bargaining approaches, the outcome is often dependent on the sequencing of decisions. We are of the opinion that the Horn \& Persson approach is a fairly accurate description of a number of technology sharing agreements (e.g., the aircraft engine manufacturing example).

We have also examined the antitrust aspects of R\&D cooperation, with an emphasis on the market share restrictions that are put on such cooperative arrangements in order for them to be part of the exemption to Article 81 of the EC Treaty. The restriction states that the market share for products related to the R\&D cooperation shall not be larger than $25 \%$ when entering into the cooperation, and since our model consists of three firms only it is highly likely that neither of the potential coalitions will fit the bill. However, without considering strategic responses to such a restriction it is possible to show that the coalition between the two least efficient firms can at least come close to the $25 \%$ market share restriction. Furthermore, a market share of more than 25\% may be allowed provided that competition is not restricted too adversely.

In highly concentrated industries, which is the case that we consider, competition policy authorities would generally be reluctant to allow too much cooperation even though research \& development collaborations are provided with a block exemption from Article 81 in the EC Treaty. In particular, with a block exemption on a R\&D cooperation project it is unlikely that coordination of the production of the final product will be allowed. Another plausible sharing of technology information is one which allows the partners to produce at the lowest cost technology available. However, our concern is with a situation where not all technological 
knowledge is distributed to all coalition partners, which in our opinion is a highly likely scenario. In such a case, the coalition partners are faced with their initial cost of production, but they are able to obtain technological advances from the partners, which reduce their production costs in some dimensions complementary to a firm's own R\&D effort.

One argument for coordinating R\&D expenditures is to reduce socially wasteful R\&D effort, which would provide an additional social gain from cooperation (often due to elimination of fixed costs of R\&D). In the context of our analysis, the cost of doing research involves a quadratic cost function, and the technology advances are complementary. This implies that the eliminating R\&D undertaken by one firm does not necessarily imply a social benefit. Furthermore, to achieve the same total impact of the R\&D another coalition partner would have to increase its R\&D spending if one firm reduces his spending. Due to the quadratic R\&D cost function this would imply higher total expenditure on R\&D.

The manufacturing of aircraft engines provide a case study for the analysis, and this example shows that different coalitions can form between the leading actors in this industry. We do not, however, observe the coalitions predicted from the theory since they may contravene competition law. Whilst we have shown that the predicted technology sharing agreements can maximize welfare given the market structure, the case study reveals that the weakening of potential competition may be a factor in predicting actual sharing arrangements. For the aircraft manufacturing industry, however, RJVs may arguably not affect the possibility for other firms to enter the market. The theoretical analysis then shows that allowing a research coalition between the most efficient firms, or all leading firms, may well be welfare improving. This paper has contributed to the theory of technology sharing by looking at heterogeneous firms that all have different incentives to divulge information in R\&D joint ventures. Our ongoing research attempts to integrate competition policy into this framework.

Acknowledgement The authors would like to thank seminar participants at the University of Tromso, the University of York, Western Washington University and LMU Munich for valuable comments, and in particular Kate Rockett, Bipasa Datta, Luigi Siciliani and Øystein Foros. This paper is part of the project "The 
knowledge-based society" sponsored by the Research Council of Norway (Project 172603/V10).

\section{References}

Aghion, P., N. Bloom, R. Blundell, R. Griffith, and P. Howitt (2005). Competition and innovation: An inverted -U relationship. The Quarterly Journal of Economics 117: 701-728.

Allen, R. (1983). Collective invention. Journal of Economic Behavior and Organization 4: 1-24.

Banal-Estanol, A,. Macho-Stadler, I., and J. Seldeslachts (2008). Endogenous mergers and endogenous efficiency gains: The efficiency defence revisited. International Journal of Industrial Organization 26: 69-91.

Barros, P. (1998). Endogenous mergers and size asymmetry of merger participants. Economics Letters 60: 113-119.

Bartolini, D. (2008). Investment and merging strategies, mimeo.

Belleflamme, P. (2000). Stable coalition structures with open membership and asymmetric firms. Games and Economic Behavior 30: 1-21.

Bergstrom, T., and H. Varian (1985). When are Nash equilibria independent of the distribution of agents' characteristics? Review of Economic Studies 52: 715-718. Bloch, F. (1996). Sequential formation of coalitions in games with externalities and fixed payoff division. Games of Economic behavior 14: 90-123.

Brod, A., and R. Shivakumar (1997). R\&D cooperation and the joint exploitation of R\&D. Canadian Journal of Economics 30, 673-684.

Buchanan, J. (1965). An economic theory of clubs. Economica 32: 1-14.

Carter, A. (1989). Knowhow trading as economic exchange. Research Policy 18: $155-163$.

Chatterjee, K., Dutta, B., Ray, D., and K. Sengupta (1993). A theory of noncooperative coalitional bargaining. Review of Economic Studies 60: 463-477 
Dasgupta, P. and J. Stiglitz (1980). Industrial structure and the nature of innovative activity. The Economic Journal 90: 266-293.

d'Aspremont, C., and A. Jacquemin (1988). Cooperative and noncooperative R\&D in duopoly with spillovers. American Economic Review 78: 1133-1137.

De Bondt, R. (1997). Spillovers and innovative activities. International Journal of Industrial Organization 15: 1-28.

Deneckere, R. and C. Davidson (1985). Incentives to form coalitions with Bertrand competition. The Rand Journal of Economics 16: 473-486.

Eaton, B.C., and M. Eswaran (1997). Technology-trading coalitions in supergames. Rand Journal of Economics 28: 135-149.

Farrell, J. and C. Shapiro (1990). Horizontal merger: An equilibrium analysis. American Economic Review 80: 107-126.

Fried, D. (1984). Incentives for information production and disclosure in a duopolistic environment. Quarterly Journal of Economics 99: 367-381.

Gal-Or, E. (1985). Information sharing in oligopoly. Econometrica 53: 329-343.

Gal-Or, E. (1986). Information transmission-Bertrand and Cournot equilibria. Review of Economic Studies 53: 85-92.

Giotakos, D., L. Petit, G. Garnier, and P. De Luyck (2001). General Electric/Honeywell-An insight into the Commission's investigation and decision. Competition Policy Newsletter, Number 3, October 2001.

Gil Molto, M.J., Georgantizis, N., and V. Orts (2005). Cooperative R\&D with endogenous technology differentiation. Journal of Economics \& Management Strategy 14: 461-476.

Goyal, S., and J.L. Moraga-Gonzáles (2001). R\&D networks. RAND Journal of Economics 32: 686-707.

Gulger, K. and R. Siebert (2007). Market power versus efficiency effects of mergers and research joint ventures: Evidence from the semiconductor industry. The Review of Economics and Statistics 89: 645-659.

Halmenschlager, C. (2004). R\&D-cooperating laggards versus a technological leader. Economics of Innovation and New Technology 13: 717-732. 
Henriques, I. (1990). Cooperative and noncooperative R\&D in Duopoly with spillovers: Comment. American Economic Review 80: 638-640.

Horn, H., and L. Persson (2001). Endogenous mergers in concentrated markets. International Journal of Industrial Organization 19: 1213-1244.

Kabiraj, T., and A. Mukherjee (2000). Cooperation in R\&D and production: a three-firm analysis. Journal of Economics 71: 281-304.

Kamien, M., Muller, E., and I. Zang (1992). Research joint ventures and R\&D cartels. American Economic Review 82: 1293-1306.

Kamien, M., S. Oren, and Y. Tauman (1992). Optimal licensing of cost-reducing innovation. Journal of Mathematical Economics 21: 483-508.

Kamien, M., and I. Zang (1990). The limits to monopolization through acquisition. Quarterly Journal of Economics 2: 465-499.

Kamien, M., and I. Zang (1991). Competitively cost advantageous mergers and monopolization. Games of Economic Behaviour 3: 323-338.

Kamien, M. and I. Zang (2000). Meet me halfway: Research Joint Ventures and absorptive capacity. International Journal of Industrial Organization 18: 9951012.

Leahy, D., and J.P. Neary (1997). Public policy towards R\&D in oligopolistic industries. American Economic Review 87: 642-662.

Lerner, J., and J. Tirole (2004). Efficient patent pools. American Economic Review 94: 691-711.

Lerner, J., and J. Tirole (2005). The economics of technology sharing: Open source and beyond. Journal of Economic Perspectives 19: 99-120.

Milliou, C. (2009). Endogenous protection of R\&D investments. Canadian Journal of Economics 42: 184-205.

Okuno-Fujiwara, M., Postlewaite, A., and K. Suzumura (1990). Strategic information revelation. Review of Economic Studies 57: 25-47.

Ray, D., and R. Vohra (1997). Equilibrium binding agreements. Journal of Economic Theory 73: 30-78. 
Ray, D., and R. Vohra (1999). A theory of endogenous coalition structure. Games of Economic Behaviour 26: 286-336.

Reinganum, J. (1985). Innovation and industry evolution. The Quarterly Journal of Economics 99: 81-99.

Röller, L-H., R. Siebert and M. Tombak (2007). Why firms form (or do not form) RJVs. The Economic Journal 117: 1122-1144.

Salant, S., Switzer, S., and R. Reynolds (1983). Losses from horizontal merger: The effects of an exogenous change in industry structure on Cournot-Nash equilibrium. The Quarterly Journal of Economics 98: 185-199.

Seade, J. (1980). The stability of Cournot revisited. Journal of Economic Theory 48: 479-489.

Shapiro, C. (1986). Exchange of cost information in oligopoly. Review of Economic Studies 53: 433-446.

Stiegler, G.J. (1950). Monopoly and oligopoly by merger. American Economic Review 40: 23-34.

Straume, O.R. (2006). Managerial delegation and merger incentives with asymmetric costs. Journal of Institutional and Theoretical Economics 162: 450-469.

Suzumura, K. (1992). Cooperative and noncooperative R\&D in an Oligopoly with spillovers. American Economic Review 82: 1307-1320.

Vasconcelos, H. (2006). Endogenous mergers in endogenous sunk cost industries. International Journal of Industrial Organization 24: 227-250.

Vickers, J. (1986). The evolution of market structure when there is a sequence of innovations. Journal of Industrial Economics 35: 1-12.

Vives, X. (1984). Duopoly information equilibrium: Cournot and Bertrand. Journal of Economic Theory 34: 71-94.

von Hippel, E. (1987). Cooperation between rivals: Informal knowhow trading. Research Policy 16: 291-302.

Wiethaus, L. (2005). Absorptive capacity and connectedness: Why competing firms also adopt identical R\&D approaches. International Journal of Industrial Organization 23: 467-481. 


\section{Appendix 1}

The equations of lines $\mathrm{A}, \mathrm{B}, \mathrm{C}, \mathrm{D}, \mathrm{H}, \mathrm{J}$ and $\mathrm{K}$ in the figures are:

$$
\begin{aligned}
& A \quad: \quad c= \frac{4 \gamma-6}{8 \gamma^{2}-17 \gamma-3} \equiv \underline{c} \\
& B \quad: \quad c= \frac{2-\gamma}{6(1-\gamma)} \equiv \bar{c} \\
& C \quad: \quad c=\frac{\gamma(\gamma-3)}{14 \gamma^{2}-5 \gamma-3} \\
& D \quad: \quad c=\frac{\gamma(\gamma-3)}{22 \gamma^{2}-22 \gamma+3} \\
& H \quad: \quad c \equiv d(\gamma)=\frac{-6 \gamma\left(-2166 \gamma+4828 \gamma^{2}-4224 \gamma^{3}+1280 \gamma^{4}+333\right)}{3\left(5229 \gamma-17292 \gamma^{2}+30608 \gamma^{3}-29440 \gamma^{4}+11264 \gamma^{5}-648\right)}
\end{aligned}
$$

where $\omega \equiv 62.354+554.26 \gamma^{2}-221.7 \gamma^{3}-342.95 \gamma$

$$
\begin{aligned}
J \quad: \quad c=\frac{6 \gamma\left(-1932 \gamma+4030 \gamma^{2}-3616 \gamma^{3}+1152 \gamma^{4}+333\right)}{3\left(5229 \gamma-18102 \gamma^{2}+33056 \gamma^{3}-30592 \gamma^{4}+11264 \gamma^{5}-648\right)} \\
K \quad: \quad c=\frac{\gamma^{2}(40 \gamma-54)}{\left(306 \gamma\left(1+\gamma^{2}\right)-645 \gamma^{2}-54\right)}
\end{aligned}
$$

\section{Appendix 2}

Proof of Proposition 6:

Part (i): Define $\Delta_{m} \equiv \Pi^{12}-\Pi^{13}$ and $\Delta_{n} \equiv \Pi^{12}-\Pi^{23}$, where $\Pi^{i j} \equiv \Pi_{1}^{i j}+\Pi_{2}^{i j}+$ $\Pi_{3}^{i j}$ is the industry profit with a coalition between firms $i$ and $j$, for $i, j=1,2,3$ 
with $i \neq j$. It can be shown that the following holds:

$$
\begin{aligned}
\Delta_{m} & =\frac{c(2 \gamma-1)\left(c \gamma^{2}(200 \gamma-429)+c(306 \gamma-54)+\gamma^{2}(40 \gamma-54)\right)}{2 \gamma\left(8 \gamma^{2}-17 \gamma+6\right)^{2}} \\
\Delta_{n} & =-\frac{2 c \gamma(2 c-1)(20 \gamma-27)(2 \gamma-1)}{\left(8 \gamma^{2}-17 \gamma+6\right)^{2}}>0
\end{aligned}
$$

This implies that the industry profit is highest when firms 1 and 2, i.e., the two most efficient firms, enter into a technology sharing consortium. In order to obtain a complete ranking of all the three coalition outcomes, let us define $\Delta_{r} \equiv \Pi^{23}-\Pi^{13}$ which can be written as:

$$
\Delta_{r}=\frac{c(2 \gamma-1)\left(c(306 \gamma-54)-\gamma^{2}(40 \gamma-54)+c \gamma^{2}(360 \gamma-645)\right)}{2 \gamma\left(8 \gamma^{2}-17 \gamma+6\right)^{2}}
$$

The sign on equation (21) is ambiguous, but $\Delta_{r} \geq 0$ if:

$$
c \geq \widetilde{c} \equiv \frac{\gamma^{2}(40 \gamma-54)}{\left(306 \gamma\left(1+\gamma^{2}\right)-645 \gamma^{2}-54\right)}
$$

If (22) holds, the ranking between industry profits for the three coalitions is:

$$
\Pi^{12}>\Pi^{23} \geq \Pi^{13} \geq 0
$$

If (22) is violated, the ranking of industry profit is:

$$
\Pi^{12}>\Pi^{13} \geq \Pi^{23} \geq 0
$$

To ensure that the coalition between firms 1 and 2 is the equilibrium technology sharing agreement, we need to ensure that firms 1 and 2 cannot earn higher profits without a coalition. Define $\Delta_{s} \equiv \Pi_{1}^{12}+\Pi_{2}^{12}-\Pi_{1}-\Pi_{2}$. We can show the following:

$$
\Delta_{s}=\frac{\gamma(2 \gamma-1)}{2}\left(\left(x_{1}^{12}\right)^{2}+\left(x_{2}^{12}\right)^{2}\right)-\frac{\gamma(8 \gamma-9)}{18}\left(\left(x_{1}\right)^{2}+\left(x_{2}\right)^{2}\right)>0
$$

We have already seen that the non-cooperative R\&D levels are strictly higher for firms 1 and 2 , but the factor $\frac{\gamma(2 \gamma-1)}{2}$ is larger than $\frac{\gamma(8 \gamma-9)}{18}$. To check that $\Delta_{s}>0$ 
first note that as $\gamma \rightarrow \infty, \Delta_{S} \rightarrow 0$. The area in which the equilibria that underlie $\Delta_{S}$ exist is given by $\frac{\gamma-2}{6(\gamma-1)} \equiv \bar{c}>c>\underline{c} \equiv \frac{2(2 \gamma-3)}{8 \gamma^{2}-17 \gamma-3}$ which is the area between $A$ and $B$ in Figure 1. Evaluating $\Delta_{s}$ at a point on either of these lines reveals that $\Delta_{s}>0$. Furthermore, from this point we have that $\frac{\partial \Delta_{s}}{\partial \gamma}<0$ so that $\Delta_{s} \rightarrow 0$ from above as $\gamma$ increases. Hence for parameter combinations of $c$ and $\gamma$ in the permissible range we have $\Delta_{s}>0$. Hence, we have shown part (i).

Part (ii): If we allow for all three firms to enter into a technology sharing coalition, the three-firm coalition will emerge as the equilibrium structure if $\Pi^{123}-\Pi^{12} \geq 0$, which will be the case if $c \leq d(\gamma)$ where $d(\gamma)$ is defined in the appendix. For the three-firm coalition, we need in addition to ensure that the coalition profit is greater than, or equal, the profit in the default scenario of no coalition; i.e., $\Pi^{123}-\Pi \geq 0$. These two conditions are satisfied in the area between $A$ and $H$ in Figure 2. QED. 


\section{conomics}

The Open-Access, Open-Assessment E-Journal

Please note:

You are most sincerely encouraged to participate in the open assessment of this article. You can do so by either recommending the article or by posting your comments.

Please go to:

www.economics-ejournal.org/economics/journalarticles/2010-1

The Editor

(C) Author(s) 2010. Licensed under a Creative Commons License - Attribution-NonCommercial 2.0 Germany 